\section{BIBECHANA}

A Multidisciplinary Journal of Science, Technology and Mathematics

ISSN 2091-0762 (online)

Journal homepage: http://nepjol.info/index.php/BIBICHANA

\section{BIBECHANA}

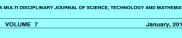

voumen

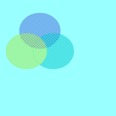

\title{
Temperature regulation in animals
}

\section{Ram Prasad Koirala*}

Dept. of Physics, M.M.A.M. Campus, Biratnagar, Nepal

Article History: Received 5 September 2010; Revised 22 October 2010; Accepted 5 November 2010

\begin{abstract}
We have studied the rate of evaporation of sweat for the body of human of two different surface areas at different temperatures. We have also studied the rate of evaporation of sweat at different values of heat produced by chemical metabolism. It is found that a thin man perspires at lower temperature than a fat man when they both produce the same heat by chemical metabolism.
\end{abstract}

\section{Keywords: Chemical metabolism; Evaporation of sweat; Normal breathing}

\section{Introduction}

Most biological processes are temperature dependent. So the body temperature must be kept within a narrow range. The chemical metabolism of food is the source of body heat. Depending on the air temperature and clothing worn, the heat generated may be needed to overcome convective and radiative loss and radiation from the skin and by the evaporation of sweat from the skin and of water from the lungs [1,2].

The evaporation of sweat is primary cooling mechanism used by the body. The temperature - control mechanisms of many warm blooded animals make use of heat of vaporization, removing heat from the body using it to evaporate from the tongue (Panting) or from the skin (sweating). Evaporation by perspiration is an important mechanism for temperature control of warm blooded animals- evaporating cooling enables humans to maintain normal body temperature in hot, dry desert climates where the air temperature may reach $55^{\circ} \mathrm{C}$ (about $130^{\circ} \mathrm{F}$ ). The skin temperature may be as much as $30^{\circ} \mathrm{C}$ cooler than the surrounding air. Under these conditions a normal person may perspire several liters per day, and this lost water must be replaced [3].

If the interior temperature begins to increase, the body first increases blood flow near the skin surface to increase convective and radiative losses and then if necessary, uses evaporative loss mechanism. Human sweats from glands located over much of the body and thus benefits from evaporation over a large surface area. As much as $1.5 \mathrm{~kg}$ sweat per hour can be evaporated from the human body under many conditions. Evaporation by perspiration is primary cooling mechanism for temperature control of human body. This mechanism can also be observed in

\footnotetext{
* Corresponding author: Ram Pd. Koirala, Dept. of Physics M.M.A.M. Campus, Biratnagar, Nepal, Email:sijuwa_3@yahoo.co.in
} 
other warm-blooded animals. In this paper we intend to study about the rate of sweat from human body in different conditions in light of physics.

\section{Theory}

The various contributions to the rate of heat loss and production of heat for a typical human adult are approximately as follows [4]:

If the area is given in square meter, the skin temperature $T_{s}$ and air temperature $T_{a}$ are given in degree Celsius, and the rate $r$ of sweating is in units of kilogram per hour, then

$$
\begin{aligned}
& \mathrm{H}_{\mathrm{m}}=\text { Rate of heat generated by metabolism } \quad\left(80 \text { to } 1600 \mathrm{~W} \text {; average } \mathrm{H}_{\mathrm{m}}=300 \mathrm{~W}\right. \text { ) } \\
& \mathrm{H}_{\mathrm{r}}=\text { Rate of heat lost by radiation } \\
& =\mathrm{D}_{\mathrm{r}} \mathrm{A}\left(\mathrm{T}_{\mathrm{s}}-\mathrm{T}_{\mathrm{a}}\right) \\
& \mathrm{H}_{\mathrm{c}}=\text { Rate of heat lost by convection } \\
& =\mathrm{D}_{\mathrm{c}} \mathrm{A}\left(\mathrm{T}_{\mathrm{s}}-\mathrm{T}_{\mathrm{a}}\right) \text { (still air) } \\
& \mathrm{H}_{1}=\text { Rate of heat lost by evaporation from the lungs } \\
& =\mathrm{D}_{1} \\
& \mathrm{H}_{\mathrm{s}}=\text { Rate of heat lost by evaporation of sweat } \\
& =\mathrm{D}_{\mathrm{s}} \mathrm{r}
\end{aligned}
$$

The D's are constants whose values are given by

$$
\begin{aligned}
& \mathrm{D}_{\mathrm{c}}=7.1 \mathrm{Wm}^{-2} \mathrm{~K}^{-1} \\
& \mathrm{D}_{\mathrm{r}}=6.5 \mathrm{~W} \mathrm{~m}^{-2} \mathrm{~K}^{-1} \\
& \mathrm{D}_{\mathrm{s}}=674 \mathrm{~W} \mathrm{~h} \mathrm{~kg}^{-1} \\
& \mathrm{D}_{1}=10.5 \mathrm{~W} \text { for normal breathing. }
\end{aligned}
$$

The value of $\mathrm{H}_{1}$ is given for normal breathing; it increases to the proportion of rate of breathing. As the variation is very small, we neglect the variation.

For the body temperature to be held constant, the heat loss are related as

$$
\begin{aligned}
& \mathrm{H}_{\mathrm{m}}=\mathrm{H}_{\mathrm{s}}+\mathrm{H}_{\mathrm{r}}+\mathrm{H}_{\mathrm{c}}+\mathrm{H}_{\mathrm{l}} \\
& \mathrm{H}_{\mathrm{s}}=\mathrm{H}_{\mathrm{m}}-\mathrm{H}_{\mathrm{c}}-\mathrm{H}_{\mathrm{r}}-\mathrm{H}_{1}
\end{aligned}
$$

\section{Results and discussion}

For a given value of heat produced by chemical metabolism in a man, the rate of sweating has been found to increase with increase in air temperature. Evaporation begins at different temperature depending upon the amount of heat produced by metabolism.

With a given surface area, as heat produced by metabolism is increased, sweating is found to begin at lower temperature and the rate of sweat production is higher for larger value of heat of metabolism, $\mathrm{H}_{\mathrm{m}}$. For a typical human of $\mathrm{A}=1.0 \mathrm{~m}^{2}$, sweating begins around air temperature of $32^{0} \mathrm{C}\left(\mathrm{r}=0.0022 \mathrm{kgh}^{-1}\right), 16^{0} \mathrm{C}\left(\mathrm{r}=0.0057 \mathrm{kgh}^{-1}\right), 2^{0} \mathrm{C}\left(\mathrm{r}=0.0200 \mathrm{kgh}^{-1}\right)$ and below $0^{0} \mathrm{C}$ for $\mathrm{H}_{\mathrm{m}}=80 \mathrm{~W}, \mathrm{H}_{\mathrm{m}}=300 \mathrm{~W}, \mathrm{H}_{\mathrm{m}}=500 \mathrm{~W}$ and $\mathrm{H}_{\mathrm{m}}=1000 \mathrm{~W}$ respectively.

For a human of $\mathrm{A}=1.2 \mathrm{~m}^{2}$, sweating begins around $33^{\circ} \mathrm{C}\left(\mathrm{r}=0.0063 \mathrm{kgh}^{-1}\right), 20^{0} \mathrm{C}(\mathrm{r}=0.0179$ $\left.\mathrm{kgh}^{-1}\right), 8^{0} \mathrm{C}\left(\mathrm{r}=0.02406 \mathrm{kgh}^{-1}\right)$ and far below for $\mathrm{H}_{\mathrm{m}}=80 \mathrm{~W}, 300 \mathrm{~W}, 500 \mathrm{~W}$ and $1000 \mathrm{~W}$ respectively. 
Ram P. Koirala / BIBECHANA 7 (2011) 14-17 : BMHSS

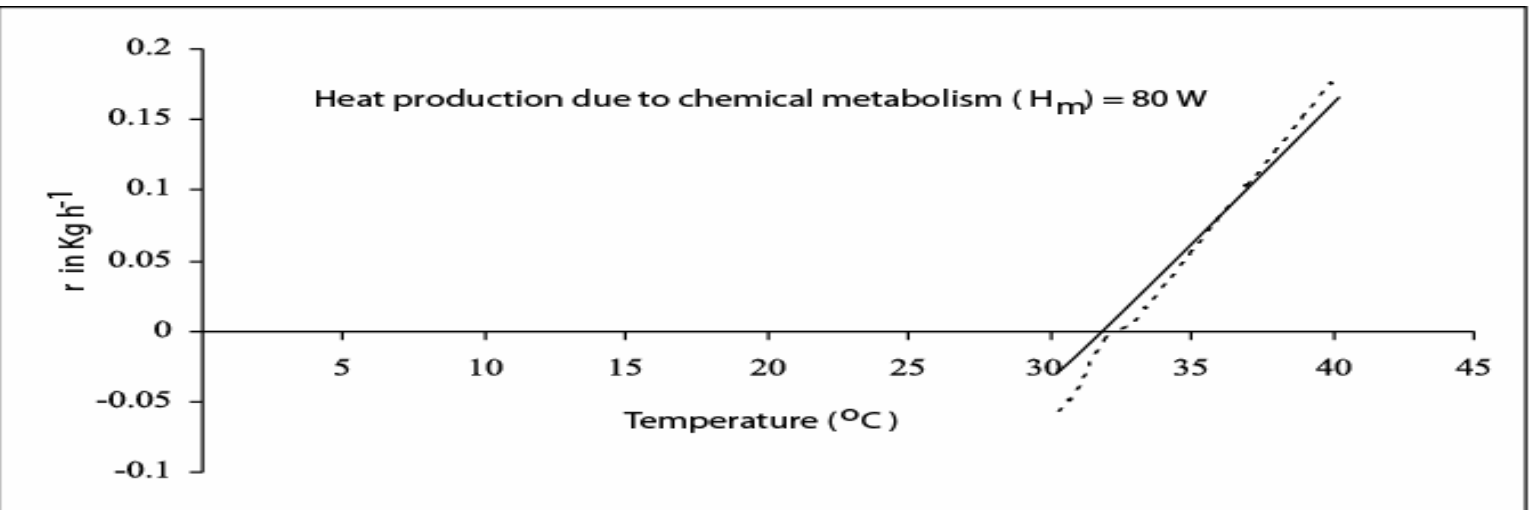

Figure : 1

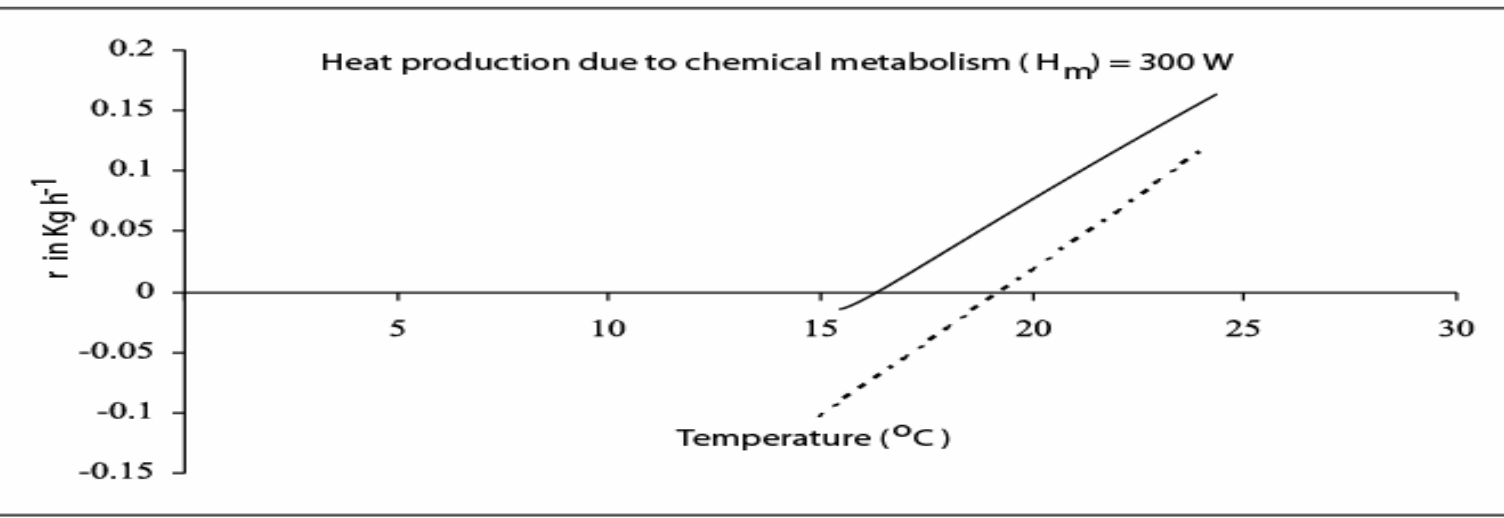

Figure : 2

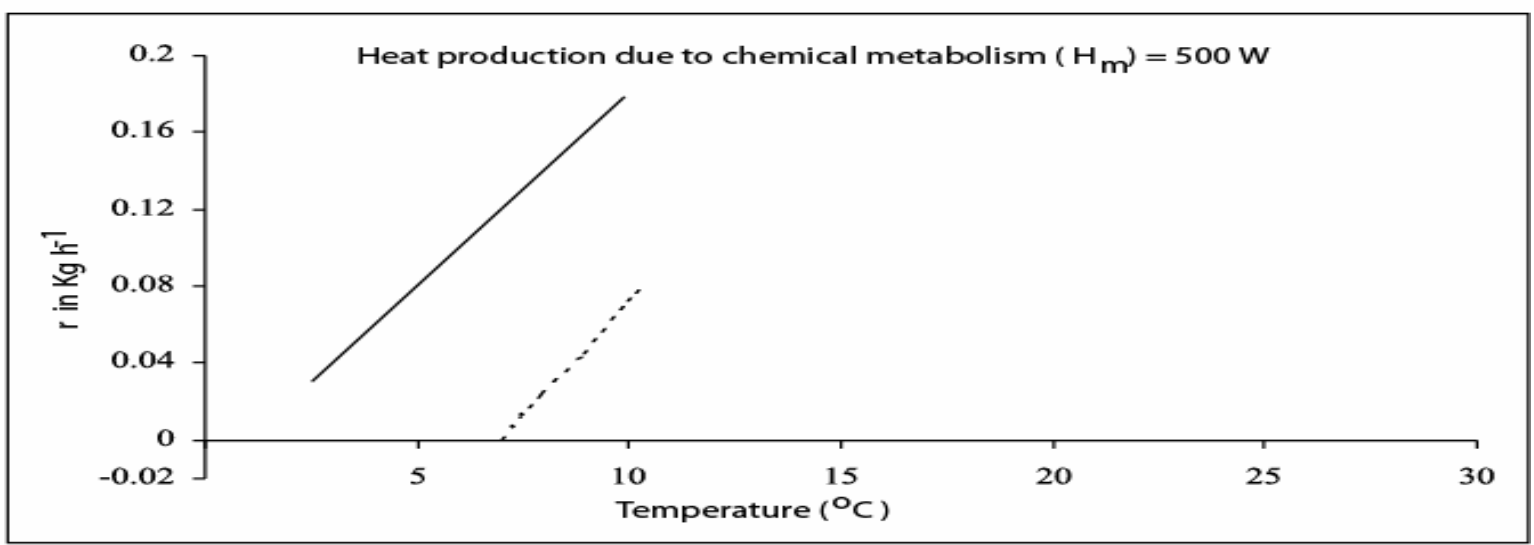

Figure : 3

Figure 1, 2 and 3: Rate of evaporation of sweat (r) verses temperature, $(\quad$ ) for a human of surface area 1.0 square metre and (.......) for human of surface area 1.2 square metre.

Thus rate of perspiration varies with the heat produced by the chemical metabolism and with the temperature of air. The evaporation of sweat forms an important mechanism for the temperature control of human body. The constant body temperature of other warm blooded animals can also be explained on the principle of evaporation by perspiration. 


\section{Conclusions}

A thin man perspires at lower temperature than a fat man when they both produce the same heat by chemical metabolism. At higher temperature rates of sweating are nearly the same for fat and thin man.

\section{Acknowledgement}

I gratefully acknowledge Associate Professor Devendra Adhikari, presently in T.M. Bhagalpur University, for his valuable suggestions and inspiring discussions.

\section{References}

[1] T.C. Ruch and H.D. Patton; Physiology and Biophysics Vol. 3, W.B. Saunders Co. Philadelphia, Chap.5 ( 1973 ).

[2] H. Bornd, Scientific American ( 1981) 146.

[3] F.W.Sears, Zemnasky et.al., University Physics, 11th ed. Pearson Education, Delhi, (2004).

[5] J .W. Kane and M.M. Sterntheim, Physics, John Willey and Sons 2nd ed. ( 1948 ) p. 260.

\section{Further Readings}

J.R. Cameron and J. G. Skofronick, Medical Physics, John Willey and Sons Inc. New York ( 1978). 